Forthcoming in Archiv für Geschichte der Philosophie. Please cite published version.

\title{
Aristotle on Self-Sufficiency, External Goods, and Contemplation
}

\author{
Marc Gasser-Wingate
}

Part of the justification of the contemplative life Aristotle offers at EN X.6-8 rests on the claim that contemplation is the most self-sufficient form of virtuous activity. Virtuous activity of any sort, Aristotle tells us, will require some basic necessities, but contemplation distinguishes itself by being an activity we can perform without relying on others: the just or courageous individual needs other people to be just or courageous towards, or just and courageous with, while the philosopher can contemplate alone (X.7 1177a27-b1). Aristotle says that this agrees with his previous arguments, and it's natural to think, for reasons I'll be reviewing below, that he is referring here to his characterization of eudaimonia as something self-sufficient, that is, something which "on its own makes life choiceworthy and lacking in nothing” (I.7 1097b14). ${ }^{1}$

But as a number of commentators have pointed out, such an interpretation makes Aristotle's defense of the contemplative life rather problematic. ${ }^{2}$ For there's no immediate reason why the kind of self-sufficiency mentioned in I.7 would require that an individual engage in activities which do not rely on others. After all, if our life is "lacking in nothing" then in particular it isn't lacking in contemplative colleagues, and so it's not obvious why the fact that we can contemplate alone would make us (or our contemplative activity) especially selfsufficient. $^{3}$ Now, it may be tempting to think that leading a frugal existence is a good way to achieve self-sufficiency: perhaps the best way to make our lives

\footnotetext{
${ }^{1}$ In what follows I will be using endaimonia, "happiness," and "human flourishing" interchangeably. All of these should be taken to denote the highest human good.

${ }^{2}$ See for instance Brown's notes to Ross (2009: 265), Kraut (1989: 299), Nussbaum (2001: 376), and, more recently, Hitz (2011: 1-4).

${ }^{3}$ Nor indeed is it immediately clear how anything could be more or less self-sufficient in the first place, since the definition of self-sufficiency in I.7 is an absolute-a candidate good (or set of goods) is either self-sufficient or not, depending on whether or not it makes our lives choiceworthy and lacking in nothing. To further complicate things, Aristotle ascribes self-sufficiency to both individuals and activities (including eudaimonia), and also speaks of our natures and lives being self-sufficient, and of the self-sufficiency of cities, and even of the self-sufficiency of certain types of knowledge. More below on his many uses of the term, and how we might reconcile them.
} 
"lacking in nothing" is for us to minimize our needs, and engage only in pursuits that require very little. But Aristotle doesn't generally seem concerned with the number of resources necessary for a flourishing human life, and tells us quite explicitly that endaimonia will require a lot: we need friends and fellow citizens because we are by nature political (I.7 1097b11), we need at least enough luck to avoid Priam's wretched fate (I.8 1100a5-9), and we need a broad array of external goods as prerequisites for different kinds of virtuous activity-money, political power, health, honor, good birth, tolerable looks, decent children. If endaimonia can require all these resources and still be self-sufficient, it's not clear why contemplation's being a low-resource activity would contribute to its self-sufficiency.

There are broadly two interpretive approaches one could take here. The first is to claim that Aristotle is simply invoking different sorts of self-sufficiency in these passages: many have taken his emphasis on the philosopher's independence from others to be one reason among many to treat $E N$ X.6-8 as separate from what precedes it, and in particular from his invocation of self-sufficiency in I.7. ${ }^{4}$ The second approach is to develop a single interpretation of self-sufficiency that would allow us to make sense of his invocation of self-sufficiency in I.7 as well as his argument that contemplation is the most self-sufficient form of virtuous activity. For instance, some commentators have taken the self-sufficiency at issue in both contexts to be a matter of some activity's finality: ${ }^{5}$ endaimonia makes our lives choiceworthy and lacking in nothing by being sufficient, on its own, to structure our various practical pursuits-at least when adopted as the ultimate end of these pursuits. And contemplation is the activity best suited to play this structuring role, and therefore the most self-sufficient activity. ${ }^{6}$

I think we should favor this second interpretive approach, but resist the thought that an activity's self-sufficiency merely reflects its finality. My goal in this paper is to develop a different interpretation, on which the notion of

\footnotetext{
${ }^{4}$ Nussbaum (2001: 373-77), for instance, takes Aristotle's discussion of self-sufficiency to serve as evidence that X.6-8 is a Platonic aside independent from the rest of the $E N$, and Brown (forthcoming) distinguishes between "solitary" and "political" senses of self-sufficiency, arguing that the former is invoked in EN X, and the latter everywhere else. See also Curzer (1990: 422-24) on these points. Aristotle's use of self-sufficiency has also been invoked to motivate the view that $E N \mathrm{X}$ focuses exclusively on the intellectual part of our human nature-on which see Cooper (1975: 168-80) or Whiting (1986).

${ }^{5}$ Here and below I use "final" ( $\left.\tau \epsilon ́ \lambda \epsilon \iota\right)$ ) and its cognates as terms of art (except in text [4], where "complete" is a more appropriate translation). Something is final insofar as it serves as an end for the sake of which we pursue other goods or activities. Like self-sufficiency, finality comes in degrees-happiness is the most final of human goods.

${ }^{6}$ Different versions of this position are defended in Cooper (2003) and Lear (2004). I'll be pointing out some difficulties with this interpretation (and interpretations that posit two senses of self-sufficiency) below.
} 
self-sufficiency at play in both I.7 and X.6-8 stems chiefly from Aristotle's conviction that endaimonia is something we pursue by our own means, by engaging in

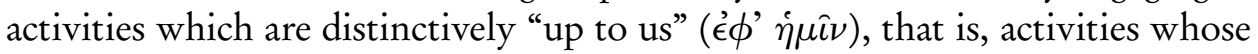
successful unfolding depends on their agent rather than on luck or fortuitous external circumstances. I'll argue that this kind of self-sufficiency-self-sufficiency as a form of independence from external contributors to some activity-is implicit in Aristotle's treatment of external goods, as well as his discussion of self-sufficiency in political contexts. I'll then explain how, on this reading, a self-sufficient activity would "on its own" make our lives "choiceworthy and lacking in nothing," as Aristotle tells us in EN I, and why contemplation would plausibly turn out to be the most self-sufficient form of virtuous activity, as Aristotle tells us in EN X. ${ }^{7}$

\section{Self-Sufficiency in $E N$}

Happiness, Aristotle claims in EN I.7, is final and self-sufficient. Happiness is (unqualifiedly) final because we find it worth pursuing for its own sake and not for the sake of something else more than any other activity (1097a30-34), and self-sufficient because it "on its own makes life choiceworthy and lacking in nothing" (1097b14-15). These are presented as formal characteristics of happiness; features any account of happiness must include in order to count, nominally, as an account of happiness. And at first brush the self-sufficiency mentioned here suggests that any such account would have to be a highly comprehensive one: it seems that a happy, self-sufficient life will lack nothing at all, and that happiness will therefore include any good whose absence would leave our life "lacking" in some respect.

Now, this is not to say that happiness must include all goods whatsoever, or include maximal amounts of these goods. Aristotle plainly doesn't intend his account of a flourishing human life to include, say, all the pleasures one could possibly experience, or any sort of honor one might achieve-and certainly not in just any amount. ${ }^{8}$ Nor indeed does what Aristotle says here necessarily imply that happiness comprehends a variety of goods which, taken together, make a life worth choosing. Happiness could just be a single good (virtuous activity) that makes our lives choiceworthy and "lacking in nothing" when we have it-lacking in nothing of significance, that is, because nothing is more choiceworthy than

\footnotetext{
${ }^{7}$ This reading is, I think, briefly alluded to in Broadie (1991: 52-53; 424-25), Gauthier and Jolif (1970: 52), and Kraut (1989: 298-99). It also agrees on a number of points with the discussion of self-sufficiency in Hitz (2011), though the focus there is mostly on the self-sufficiency of friendship. One of my main aims here is to spell out the sort of "independence" at issue, and explain how this independence might help us make sense of the criterial use of self-sufficiency in I.7.

${ }^{8}$ As is well brought out in White (1990: 113).
} 
a life of virtue. ${ }^{9}$ The self-sufficiency requirement presented in EN I.7 is thus orthogonal to broader interpretive disputes concerning Aristotle's account of happiness: happiness could be self-sufficient as an inclusive combination of many goods, but it could also be self-sufficient if it turns out to consist in the single good that is virtuous activity. ${ }^{10}$

It remains clear, however-whatever exactly endaimonia turns out to be-that a happy life will require a number of different goods. Either these goods will be required as constitutive parts of a happy human life, or, if happiness just is virtuous activity, these goods will be required, minimally, as prerequisites for our acting virtuously. In both cases, our lives would be lacking without these goods-because they are intrinsically good constituents of our happiness, or simply because we could not act virtuously (and so could not be happy) without them. Thus on anyone's account, we must have a number of goods at our disposal in order to be happy. And this is so because a happy life must be self-sufficient, in the sense Aristotle articulates in I.7. ${ }^{11}$

But then at X.7 1177a27-b1, Aristotle also says the following: ${ }^{12}$

[1] Self-sufficiency will belong most to the activity of contemplation. For the philosopher, the just individual, and all the rest equally need the necessities of life, but once these are adequately supplied for all, the just individual will still need people towards whom and with whom he might act justly, and likewise for the temperate, the brave, and the others. But the philosopher can engage in contemplation by himself, and all the more so the wiser he is. He will perhaps do this better with colleagues around, but he remains the most self-sufficient all the same.

The self-sufficiency mentioned here seems to be a quality activities possess to a greater extent the fewer resources we need to perform them. Any kind of activity has some basic prerequisites, but once these are secured contemplation's

${ }^{9}$ For readings along these lines, see for instance Heinaman (1988), Kenny (1992: 24-42), Kraut (1989: 294-300), Labarrière (2003), or Lear (2004: 47-71). Readings on which happiness includes various intrinsic goods are defended in Ackrill (1974), Cooper (1975: 122), Devereux (1981), Gauthier and Jolif (1970: 53), Irwin (1999), Keyt (1978: 138-39), and Whiting (1986).

${ }^{10} \mathrm{I}$ take the argument to this effect in Kraut (1989: 298) to be convincing-and see also Heinaman (1988) against the view that Aristotle's self-sufficiency requirement implies a "comprehensive" view of happiness. (Cards on the table: I think happiness just is virtuous activity. But I also think what I have to say about self-sufficiency here is compatible with a range of different interpretations of endaimonia-though it does complicate certain arguments for or against these interpretations. For the sake of simplicity I will sometimes identify endaimonia with virtuous activity in what follows-though I will formulate things in a non-committal way where it makes a difference.)

${ }^{11}$ Lear (2004: 48-49) argues that the fact that certain goods are required as prerequisites for virtuous activity does not affect the self-sufficiency of happiness. I'll argue below that there is unambiguous evidence this is not so: our need for such prerequisites does limit our self-sufficiency.

${ }^{12}$ The translations of $E N$ in this paper are adaptations of Ross (2009). 
independence from others makes it more self-sufficient than any of the moral virtues discussed prior to book X. And this is presented (at 1177a12-13) as one of the reasons why contemplation is the highest and most final of the virtues-a point Aristotle had already intimated in his account of happiness in book I. ${ }^{13}$

Now, there are some immediate difficulties involved in reconciling [1] with what Aristotle says in I.7. For starters, note that self-sufficiency, as Aristotle uses the notion in [1], is a gradable notion: contemplation is said to be the most self-sufficient activity, or at least more self-sufficient than various forms of morally virtuous activity. The self-sufficiency criterion in I.7, by contrast, is an absolute. Note also that in [1] Aristotle ascribes some degree of self-sufficiency to both the activity of contemplation and to those engaged in this activity-the philosopher is said to be most self-sufficient, not just his contemplative activity. But the criterion in I.7 is meant to describe eudaimonia-which is an activity, arguably, or else an activity together with other intrinsic goods, but certainly not an individual. There is, finally, a somewhat broader difference in the role self-sufficiency plays in each context. For in I.7, self-sufficiency is used to describe what happiness is. But prima facie the question what happiness is is separate from the question how anyone might achieve happiness, or what sorts of activities might make us happy, and how many resources these activities require. Yet in X.6-8, and in passage [1] in particular, Aristotle seems concerned with this latter set of questions: he seems to be telling us that low-resource activities are the way to achieve happiness. And this might all seem orthogonal to the claim that happiness is itself a self-sufficient thing, in the criterial sense at play in I.7.

But these initial difficulties are not as problematic as they might appear. Consider the first. It's true that self-sufficiency is invoked as an absolute in I.7. But presumably this absolute can be approximated, or fulfilled to a greater or lesser extent-even ignoring Aristotle's discussion in X.6-8, it would be natural to think that something might count as more self-sufficient the more choiceworthy and less "lacking" it makes a life. On this reading, the absolute use of "self-sufficient" would simply denote a sufficiently high degree of self-sufficiency (just as "tall" denotes a sufficiently high degree of tallness). Human happiness would thus count as self-sufficient in virtue of its being highly self-sufficient, or as self-sufficient as any human activity could possibly be. ${ }^{14}$

As for the locus of self-sufficiency, I think we can draw a straightforward connection between the self-sufficiency of activities and the self-sufficiency of indi-

\footnotetext{
${ }^{13}$ See for instance 1098a16-18 and 1099a29-31.

${ }^{14}$ There's some independent motivation for reading Aristotle this way, since he suggests elsewhere (Pol 1253a29) that the highest degree of self-sufficiency would not be possible for any human being, but only for "a beast or a god." (Presumably the life of a beast is not choiceworthy, so strictly speaking only a god could achieve complete self-sufficiency, in the sense at play in I.7.)
} 
viduals: an individual counts as self-sufficient insofar as the activity characteristic of the kind of life she leads is self-sufficient. A philosopher, on this reading, would be self-sufficient because contemplation is self-sufficient, and her contemplative activity determines the sort of life she leads. ${ }^{15}$ There's some direct evidence of this way of speaking at X.7 1177b21-24, where Aristotle tells us that various qualities ascribed to the happy person, including self-sufficiency, are so ascribed in

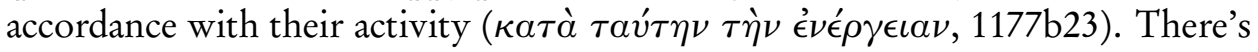
some indirect evidence, too: at times Aristotle describes as self-sufficient the lives of the self-sufficient (cf. [2], below), where again what seems to be at stake is the sort of activity that characterizes the life in question.

And finally, though the self-sufficiency criterion does not itself tell us how we might achieve happiness, or how many resource this would require, it would be quite reasonable to draw some broad conclusions on the matter from its invocation in I.7. For suppose we accept that endaimonia must make our lives choiceworthy and lacking in nothing. There seem to be roughly two ways this criterion could be met. On the one hand, eudaimonia might make for a choiceworthy life in which all our significant needs are met, however many they may be-that is, a life that might require a lot, but is always well supplied, and so does not lack anything. On the other, eudaimonia might make for a choiceworthy life in which we need nothing at all, or at least nothing beyond the most basic necessities-that is, a life that is frugal, and therefore doesn't have much it could possibly lack. And one might think that this latter point is the one Aristotle emphasizes in his discussion of contemplation: contemplation is a low-resource activity, and thus highly self-sufficient-highly self-sufficient because a contemplative life will be choiceworthy and have few needs, and so could not possibly be lacking in much.

The more pressing difficulty, I think, is that such frugal approaches to happiness plainly conflict with Aristotle's broader discussion of virtuous activity. For Aristotle has no qualms about incorporating a broad range of goods in his account of the moral virtues. We're told, for instance, that the munificent will need to "spend large amounts with good taste" (IV.2 1222b1), that the magnanimous will need honors sufficient to satisfy their ample self-esteem (IV.3 1123b13-15), and even that the temperate will need an abundance of resources (X.8 1178a33). In general, Aristotle explains, "more things are needed the greater and nobler the deeds" (X.8 1178b2-3). Indeed some of his remarks in I.7 already suggest this: right after introducing the self-sufficiency criterion, Aristotle adds that it should

\footnotetext{
${ }^{15}$ We need not spend all our time contemplating to lead a characteristically contemplative life, nor even take contemplation to be the ultimate purpose of all our actions, though it must act as an overarching, life-shaping concern. For different takes on the relationship between activities and the lives they characterize, see Broadie and Rowe (2002: 437-38), Cooper (1975: 155-68), Keyt (1978: 145-46), or Lear (2004: 201-204).
} 
not be understood as "that which is sufficient for a man by himself, for one who lives a solitary life, but also in relation to his parents, children, wife, and in general to his friends and fellow citizens" (1097b8-11), and it's natural to think that the inclusion of family, friends and fellow citizens here will require more goods than would be necessary for a solitary human being. ${ }^{16}$ So even if leading a frugal life seemed a natural way to meet the self-sufficiency criterion advanced in I.7, this would not coincide with Aristotle's discussion of moral virtue throughout $E N$, which makes it clear that human flourishing requires quite a lot.

Now, one could simply claim that Aristotle has two distinct senses of selfsufficiency in mind-one on which lower-resource activities are more self-sufficient, and another on which the amount of resources required is immaterial. But there are good reasons to resist this kind of approach. The most important one is that Aristotle's discussion in X.7 rehearses a number of criteria which were introduced in I.7-8, where endaimonia is described as active, chosen for its own sake, part of a serious life, continuous, stable, self-sufficient, and pleasant. Aristotle's argument in X.7 is that contemplation exhibits these features more than any other activity, and he explicitly says that this is "in agreement with what was said before" (1177a18-19). But outside I.7 there is only one prior passage in $E N$ where self-sufficiency plays any significant role (in IX.9, as part of Aristotle's discussion of friendship), and that passage refers back to the characterization of happiness in I.7. So it's not clear what Aristotle could be alluding to here apart from his use of self-sufficiency as a criterion for endaimonia.

A better approach, to my mind, is to try to articulate a single conception of self-sufficiency that would account for the various passages in which we find the notion invoked, and put to apparently different uses. But before attempting this, I want to say a bit more about the constraints I think such an interpretation would have to meet. The first constraint concerns the scope of the self-sufficiency requirement. I mentioned above that happiness would require a range of different goods, and that it would require these goods because happiness is self-sufficient. But self-sufficiency is not something we achieve merely by having a lot of goods at our disposal. ${ }^{17}$ Consider for instance what Aristotle says at Pol 1280b30-35: ${ }^{18}$

[2] A state is not the mere sharing of some common location, and doesn't

\footnotetext{
${ }^{16}$ This passage could also be understood as "self-sufficient for his parents, children, ...," suggesting that an individual's happiness would include the happiness of his entourage (cf. Irwin (1999: 182)). I think it's more plausible to read this passage as emphasizing the political nature of individual human beings, but on either reading more goods will be required for self-sufficiency: we need more goods to make others happy, but we also need more goods to make ourselves happy as political beings (since we need virtuous friends, healthy children, and so on).

${ }^{17}$ Contra Brown (forthcoming: 6).

${ }^{18}$ Here and in passage [6], below, I adapt Reeve's translation.
} 
exist for the purpose of preventing mutual wrongdoing and exchanging goods. These conditions must be present if indeed there is to be a state, but even if all of them are present there is not yet a state-a state is, rather, a community of households and families that live well, for the sake of a final and self-sufficient life.

The "final and self-sufficient" life alluded to here is presumably a bappy life-which Aristotle picks out using the same criteria he invokes in EN I.7. And what he tells us here is that even the life led by those in a society that distributes goods efficiently and is governed well enough to keep these goods secure might fail to be a happy one. Elsewhere Aristotle explains that a state exists for the sake of living well and achieving happiness, and not for the sake of mere life-for we can survive without a state, and even to some degree on our own (cf. Pol 1252b27ff; 1321b15-18). So commerce and exchange do contribute to our self-sufficiency, by providing us with the resources necessary for happy life. But they don't themselves guarantee that we live a happy, self-sufficient life.

Aristotle makes a similar point in his discussion of friendship: unlike utilityor pleasure-friends, virtue-friends are not there simply to help us acquire goods like money, food, or other things we need as prerequisites for a flourishing human life. The value of virtue-friends stems from the fact that their collaboration improves virtuous activities we already engage in-and such friends are a crucial component of a self-sufficient life even though they aren't helping us (qua virtuefriends) secure goods without which we couldn't engage in virtuous activity (IX.9 1169b23-30). ${ }^{19}$ So self-sufficiency is not just a matter of our having certain goods at our disposal: we could have all the prerequisites necessary for our various pursuits and nonetheless fail to be self-sufficient.

This constraint should come as no surprise. For having various goods at our disposal does not itself guarantee that we pursue any particular activity, or indeed that we pursue any activity at all. If I'm right that individuals count as selfsufficient when their lives are characterized by a self-sufficient activity, then it's plain that the mere possession of prerequisites for some activity would not make anyone self-sufficient. In fact, Aristotle suggests elsewhere that accumulating too many goods would be an impediment to our happiness: we need a certain number of goods to be self-sufficient, but self-sufficiency does not always increase with the amount of goods we possess (cf. EN VII.13 1153b23-24 and Pol 1256b30ff). We would need to put our resources to good use.

Still, we shouldn't conclude from this that our need for prerequisites has no bearing at all on our self-sufficiency. It's sometimes suggested that Aristotle only appeals to the self-sufficiency of contemplation as a final end, that is, as an activity

\footnotetext{
${ }^{19} \mathrm{~A}$ convincing argument to this effect can be found in Hitz (2011: 18-23).
} 
whose pursuit as a final end guarantees, on its own, the choiceworthiness of our lives. On this sort of view our self-sufficiency is not affected by our need for prerequisite goods: Aristotle is assuming the prerequisites are there, and then claiming that contemplation (when treated as a final end) will structure our lives in a way that guarantees their choiceworthiness, without the addition of any further good. ${ }^{20}$ If this is right only goods affecting the choiceworthiness of our lives could pose a threat to our self-sufficiency.

But it seems hard to reconcile such an interpretation with what Aristotle says later in X.8. After arguing that happiness is contemplation, he tells us that:

[3] As humans, we will still need external prosperity, too; for our nature is not self-sufficient for the purpose of contemplation, but our body also must be healthy and must have food and other attention. But we must not think that many or great things are needed for he who is to be happy [...] Self-sufficiency and action do not involve excess, and we can do noble acts without ruling earth and sea. (1178b33-79a5)

Now, Aristotle speaks in this passage of our human natures being self-sufficient for contemplation, rather than contemplators or their contemplative activity being self-sufficient. But in context the implication is clear: as human creatures we will need certain basic goods even for low-resource activities like contemplation, and this sets a limit on the degree of self-sufficiency we can hope to attain in our contemplative activity, and so a limit on the degree of self-sufficiency that belongs to buman contemplation. Evidently our basic needs for health and nourishment are taken to pose a threat to the self-sufficiency of the contemplative life-if they didn't, Aristotle wouldn't need to emphasize that we can be virtuous with moderate resources. Yet food and drink, for Aristotle, do not contribute to the choiceworthiness of our lives-they're the sorts of things necessary for mere life, and he explicitly tells us that having them would not make anyone's life worth choosing (see e.g. VII.4 1147b24-31). So self-sufficiency cannot be self-sufficiency concerning only those goods that make our lives choiceworthy ones. For as Aristotle makes clear in this passage, our need for even the most rudimentary goods is a qualification on our self-sufficiency.

There are therefore two constraints on an interpretation of the notion of self-sufficiency at play in these passages-assuming, as I think we should, that Aristotle is indeed using a single, univocal notion in his argument. The first is that self-sufficiency be diminished by our need for even the most basic goods: this is why our animal needs are a limiting condition on our self-sufficiency, even when we lead a contemplative life. The second, as previously noted, is that self-sufficiency not follow merely from our possessing the goods necessary for

\footnotetext{
${ }^{20}$ For this reading of self-sufficiency, see in particular Lear (2004).
} 
our survival and the pursuit of virtuous activity: self-sufficiency is not directly commensurate with the level of resources at our disposal.

In what follows I will defend an interpretation of self-sufficiency which meets these constraints-and which has independent textual support. I will argue that the notion of self-sufficiency at play in these passages is better understood as part of Aristotle's broader concern with the dependence of endaimonia on individual agents rather than on their possessions, circumstances, or good fortune. Indeed, despite including a vast array of external goods in his account of happiness, Aristotle often insists that their role is secondary, that virtuous action is ultimately up to us, and that happiness is something we must achieve rather than a state we might find ourselves in. I will be arguing that the kind of independence from external forces we display when acting virtuously is central to Aristotle's understanding of self-sufficiency-endaimonia is fundamentally self-sufficient because virtuous activity depends on us, and contemplation is most self-sufficient because it exhibits this feature to a greater extent than any other form of virtuous activity.

Spelling out exactly how virtuous activity might be independent from forces external to us will be my concern in the next two sections of this paper. I will begin by demarcating two different roles played by external goods in the $E N$ : as necessary conditions for virtuous activity, and as cooperative goods-goods that naturally contribute to the successful achievement of certain virtuous ends. I will then describe how Aristotle reconciles each of these roles with his conviction that happiness is up to us, and show how his claims about the self-sufficiency of contemplation, in $E N \mathrm{X}$, and the self-sufficiency of happiness, in $E N \mathrm{I}$, are natural consequences of these views.

\section{Happiness and External Goods}

The conclusion of Aristotle's function argument is that happiness is "activity of the soul in accordance with virtue [...] over a complete life" (I.7 1098a16-18). In I.8 Aristotle adds that such happiness "clearly requires external goods as well; for it is impossible, or not easy, to do noble acts without the proper equipment" (1099a31). This qualification simply reflects the commonsense point that we will need resources to live a flourishing human life, even if these resources do not on their own make our lives flourishing ones.

The resources in question should be understood quite broadly, as including all goods that are not goods of our soul-that is, all goods that do not pertain directly to our distinctively human capacities. So food, wealth, social status, friends, family, physical beauty, and health, are all external goods, as is any good we might aim at producing in another person, like the health and education of our offspring, and anything that might constitute favorable circumstances for some 
action. ${ }^{21}$ Aristotle sometimes describes these goods as those that are governed or caused by chance, and tells us this distinguishes them from things like a just or temperate character, which we must develop on our own. ${ }^{22}$ External goods are therefore goods we do not possess or realize by our own devices.

Aristotle separates external goods into two categories: some "must necessarily be there as conditions of happiness," while others "are naturally cooperative

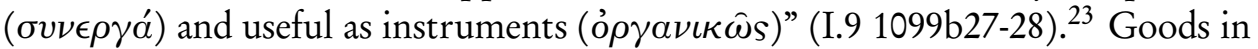
the first category can be thought of as preconditions for human happiness. Some of these are preconditions for happiness because they are required for virtuous activity-we need food, water, a moderately healthy body, as well as some amount of freedom to perform activities of any sort, and in addition to these virtuous activity will often require a fair amount of money, political standing, and so on, as well as, generally, opportunities to act virtuously. Other goods in this first category are preconditions for happiness simply because anyone who lacks them is miserable: Aristotle is no Stoic, and takes it as obvious that someone suffering a fate like Priam's is unhappy (1100a7-8). ${ }^{24}$ External goods that serve as preconditions therefore make it possible for us to be happy in one of two ways-first, by providing the conditions under which virtuous action is possible, and second, by shielding us from outright miserable conditions, under which even the most virtuous person couldn't reasonably be considered happy.

Goods in the second category, Aristotle tells us, cooperate with our activity: they serve as instruments that are naturally well-suited to some end we've set ourselves. These goods are sometimes portrayed simply as means, or instrumental goods-goods that contribute to bringing about a given end, and whose value derives from the value of that end. ${ }^{25}$ This might be right, but I think it doesn't go far enough. After all, preconditions are arguably means as well-at least in the

\footnotetext{
${ }^{21}$ For a defense of this broad reading of external goods, see Cooper (1985). Aristotle wavers a bit on the goods of the body, which he categorizes as internal goods at Rhet 1360b25-29 (cf. also Pol 1323a25-26). The thought might be that our bodies are more naturally considered part of our selves than something like wealth-though in $E N \mathrm{X}$ at least it's clear that our bodies are treated as external to us (cf. 1178b33-35).

${ }^{22}$ See for instance EN 1100b8-11, Pol 1323b27-29, MM 1206b30-37, or MM 1207b17-19.

${ }^{23}$ I take this distinction to mirror the one Aristotle draws earlier between goods whose absence mars our happiness (sometimes to the point of ruining it), and goods we use as tools ( $\delta \iota^{\prime}$ o $\rho \gamma \alpha \dot{\nu} \nu \omega \nu$ ) in our actions (1099a31ff), and also the one he draws later, in passage [1], between the "necessities" for life and our need for people with and towards whom we might act virtuously. For more details on the textual similarities between these passages, see Reeve (1992: 163-64).

${ }^{24}$ For the Stoic view, see e.g. SVF III.585 or Cicero, Tusc. Disp. I.35. For Aristotle the virtuous bear misfortunes gracefully (1100b30-32) and always make the best of their circumstances (1101a1ff), but are nonetheless deemed unhappy if the circumstances are bad enough. On Aristotle's treatment of Priam and his misfortunes, see Nussbaum (2001: 327-36).

${ }^{25}$ As for instance in Cooper (1985: 184).
} 
minimal sense that they help bring about some end-and so this wouldn't be a feature distinctive of cooperative externals. Moreover, Aristotle often describes these goods in more evocative terms, as literally working with us in some activity (as $\sigma v \nu \epsilon \rho \gamma \alpha$ goods), or as contributing to some activity just as a tool would-since, in his words, we often act "by means of friends, or wealth, or political power, as though by means of tools ( $\delta \iota^{\prime}$ ó $\left.\rho \alpha \alpha ́ \nu \omega \nu\right) "(1099 \mathrm{a} 33-\mathrm{b} 1)$.

Now, Aristotle never explicitly spells out what this sort of contribution amounts to, or how exactly it would differ from the sort of contribution made by preconditions. But he does make some suggestive remarks. At Pol 1256a1ff, for instance, Aristotle describes two ways wealth acquisition ( $\left.\chi \rho \eta \mu \alpha \tau \iota \sigma \tau \iota \kappa \eta^{\prime}\right)$ might assist household management (оєкоронєкү): in the way shuttle production assists weaving, or in the way bronze smelting assists in the sculpting of statues. The distinction between these ancillary activities rests on a distinction between the sorts of goods they provide: the former provides cooperative goods (it "provides tools," 1256a7), while the latter provides goods used as preconditions-as he puts the point here, bronze smelting "provides the matter" for sculpting, in the same way wool gathering would provide the wool needed for weaving. The point of the analogy, I take it, is that goods like wool or bronze are indispensable prerequisites for our activity: no weaving or sculpting at all is possible without them (or adequate material alternatives). Goods like a shuttle, by contrast, are not strictly necessary for weaving, but plainly improve the activity for which they were designed: we weave better with a shuttle, though we could still, perhaps with some difficulty, weave without one. Unlike preconditions, then, cooperative goods do not serve to make an activity possible. They improve an activity that we are already performing, or are already in a position to perform. ${ }^{26}$

It may be a bit harder to see how this sort of line would apply to the collaborators or targets of some activity-the case of those towards whom or with whom we might act virtuously (cf. X.7 1177a27-b1, where the collaborators are explicitly identified as $\sigma v \nu \epsilon \rho \gamma o \iota)$. For one might think that these collaborators act more like preconditions than cooperative goods-it may seem, for instance, that no courageous activity at all is possible without others to be courageous towards, or courageous with. But I think the point still stands: courageous activity does indeed require targets and collaborators of some sort, but it remains the case that courageous activity will go better with certain targets and collaborators than it does with others. On Aristotle's view, courage on the battlefield is possible in all sorts of circumstances: hitting the mean might, in some cases, require us to help

\footnotetext{
${ }^{26}$ Though I disagree with other parts of his view, I am in agreement here with Cooper's distinction between perfect and imperfect exercises of virtue, and his understanding of the role certain goods play in promoting the former. For these points, see Cooper (1985: 182-83).
} 
someone with our own bare hands, or face down some insignificant opponent. But intuitively this is not an ideal exercise of courage. An ideal exercise of courage takes place when, say, we stand our ground alongside steadfast fellow soldiers, and successfully defend ourselves and our city against a worthy, determined opponent. So while courageous activity of any sort may require others, ideal acts of courage require collaborators of a special kind-excellent fellow soldiers, a worthy invader, and so on. The collaborators that improve our activity in this way would serve as cooperative external goods. They aren't strictly required for virtuous activity (lesser fellow soldiers or opponents would do), but they do allow for an ideal or perfect display of virtue.

What this makes clear, I think, is that Aristotle should not be read as picking out some list of goods that always qualify as preconditions, and some other list of goods that always qualify as cooperative goods. The distinction is best understood as a distinction between two roles external goods can play. Thus some given good could plausibly qualify as a precondition for happiness in some contexts, and as a cooperative good in others. Friends are the most obvious case: Aristotle tells us their absence or death would make our life miserable, and so they qualify as preconditions for happiness. But (at least in virtue friendships) they are also collaborators, and contribute to our happiness by improving our own virtuous activity. ${ }^{27}$ Likewise, a lyre of some sort is a precondition for lyre-playing. But a lyre might also-if it's an especially good lyre, in the right hands-make for a particularly splendid lyre performance, and so serve as a cooperative good. ${ }^{28}$

External goods have the potential to affect our happiness in either role. Preconditions on our happiness must be in place to make virtuous activity possible and ensure some basic level of good fortune. And cooperative goods, though we may not need them to act virtuously, will affect the extent to which our virtuous activity makes us happy. For, as Aristotle tells us, ${ }^{29}$

\footnotetext{
${ }^{27}$ See Hitz (2011: 23-25) for an account of the role our friends play in improving our contemplative activity.

${ }^{28} \mathrm{Just}$ as, in our example above, some sort of opponent might be a precondition for courageous activity, but also-if the opponent is a splendid Persian army, say-improve our courageous activity, and so serve as a cooperative good. (Assuming here that great acts of courage require great opponents.)

${ }^{29}$ Aristotle doesn't directly label the goods here as goods that play a cooperative role. But it's reasonable to think that what he says must apply to cooperative externals, whether or not it also applies to preconditions. For he goes on to add (right after this, at 1153b23-24, and also in the parallel passages cited in the main text) that having too many of these goods would be an impediment to our happiness. And there's no reason why having too many goods conceived as preconditions would impede anything: they just give us more opportunities to act virtuously. The dangers associated with a glut of goods are more plausible if the goods are conceived of as cooperative ones-a connection Aristotle himself makes at Pol 1256b30ff and Pol 1323b7-12. (To be clear: a lack of preconditions would surely impede our happiness-in a rather dramatic way, since
} 
[4] No activity is complete ( $\tau \epsilon$ é $\epsilon \iota \circ)$ when it is impeded and happiness is a complete thing; this is why the happy man needs the goods of the body and external goods, i.e. those of fortune, namely, in order that he may not be

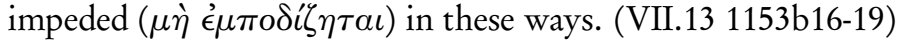

Using the same language, he calls an excessive number of friends an impediment to our happiness (1170b26-27), and an excessive amount of external goods of any sort an impediment to contemplation (1178b3-4). In the Politics he defines a happy life as a life that "expresses virtue and is without impediment" (1295a36-37), and compares the use of cooperative goods with the use a craftsman would make of his tools: tools are not more useful the more of them we have at our disposal, and having too many tools might pose a threat to our self-sufficiency, and end up doing more harm than good (1256b30ff, 1323b7-12).

Our happiness is therefore impeded either by lacking cooperative goods or by possessing too many of them. When we lack them we are like a craftsman without his tools: we lack an instrument that would naturally assist us and improve our virtuous activity. Though we may still make the best of our circumstances, our activity will not unfold as well as it might-leaving us less happy than we might have been. ${ }^{30}$ Aristotle says less about our having too many such cooperative goods-but what he does say suggests that we would spend too much time and effort looking after them (Pol 1326b10ff), which would get in the way of our actually doing what we set out to do, or that they would make us arrogant and entitled, or cause envy, or otherwise detract from the development and effective use of practical wisdom (Pol 1295b13ff).

This all seems reasonable enough. Aristotle thinks virtuous activity is possible in all sorts of suboptimal conditions: we can act generously despite being poor, say, or temperately despite being ugly. But intuitively these activities would go better if we had certain goods at our disposal: enough wealth that our generosity would actually help others, or looks good enough that we would truly need to exhibit temperance. And not too many of these goods: too many goods would require too much attention to protect and maintain, which is a distraction from actually being generous, temperate, or otherwise virtuous. So while virtuous activity will

happiness is impossible without them. My claim is only that this is not the only point Aristotle is making here. Our happiness can be impeded even when the preconditions are in place.)

${ }^{30}$ Cooper (1985: 195) resists the idea that the success of our activities has anything to do with our favoring certain circumstances in which to pursue them, arguing instead that external goods used as tools are valuable only because they make possible "continued virtuous activity in the future." But Aristotle explicitly compares the unfortunate virtuous person with "a good shoemaker," who "always makes the best of circumstances [...] and makes the best shoes out of the hides that are given him" (I.10 1101a4-5); and the emphasis here is plainly on the product of our virtuous activity, or what we are able to successfully bring about or achieve in bad circumstances (whether what we achieve is a physical object like a shoe, or just the successful performance of some activity). 
take different forms in different circumstances, some circumstances nonetheless provide the ideal setting for virtuous action, and contribute to the ideal unfolding of our acts of virtue. We might still be generous in deciding to help a friend (and correctly determining how to achieve this end) when our misfortunes hinder our efforts, and limit the effects of our generosity. But our virtuous behavior contributes most to our happiness when it succeeds unhindered. ${ }^{31}$ If this is right, our overall happiness will always depend on cooperative external goods-for some quantity of these goods is invariably required for our activities to succeed without impediment.

\section{Self-Sufficiency as Independent Activity}

I have just argued that external goods play an important role in Aristotle's account of happiness. Some goods are just prerequisites for virtuous activity, or conditions on our happiness. Others contribute to our happiness by cooperating with our activity and assisting in its successful unfolding. In each case, something must happen to us or to the world around us which we cannot bring about, or at least which we cannot fully control: we need to be healthy, have a fair amount of wealth, be born in the right city, and benefit from a good education (among other things) to be able to act virtuously at all, and even then we need some amount of good fortune for our virtuous activity to unfold without hindrance, and thus contribute to our happiness as much as it might.

Yet despite stressing our reliance on such external goods, Aristotle often and unambiguously emphasizes that we are responsible for our happiness-that virtuous action is something we do rather than something we have, or which might happen to us. As he puts it in the Politics "external goods come of themselves and by chance, while no one is just or temperate by or through chance" (VII.1 $1323 \mathrm{~b} 27-29){ }^{32}$ It's fairly easy to see why this would be the case despite our need for goods that serve as preconditions for virtuous activity: these goods are valuable only when put to judicious use, and many of them are prerequisites for any activity whatsoever. ${ }^{33}$ But the case may be less clear when it comes to cooperative

\footnotetext{
${ }^{31}$ Where success need not be understood as our securing some outcome external to our act of courage: our activity can be successful simply in virtue of its performance unfolding in the best possible way. In cases like generous activity, however, it seems natural to consider the outcome of our activity as a key factor in its overall success.

${ }^{32}$ See also EN I.8 1099a4-5, I.10 1100b12-16, III.5 1113b5-15.

${ }^{33}$ Aristotle insists, for instance, that "munificence is excellence of effect," stemming from the munificent individual's ability to create a "greater and more suitable effect" with the same expenditure as the generous one (IV.2 1122b12-19). Thus munificence requires a lot of money, but wealth alone doesn't make anyone munificent. As he puts it elsewhere, "to live well is not the same as having things without which one cannot live well” (EE 1214b16-17).
} 
goods. Aristotle tells us that "doing well or poorly does not depend on [our fortunes], but as we said human life needs these in addition, while virtuous activities are what determine happiness, and their opposites what determine its opposite" (I.10 1100b8-11). But if the success of our virtuous activities always depends on cooperative goods, and our overall happiness is affected by this success, it's not immediately clear why virtuous activity would itself "determine happiness," or why Aristotle would take our happiness to be, ultimately, up to us. By his own admission, cooperative externals depend on luck, and so are not under our control. If indeed these externals have a significant impact on our overall happiness, in what sense is virtuous activity the one privileged factor that "determines" or "causes" our happiness?

Aristotle's argument here, I take it, is based on the view that, whatever else contributes to her success, a virtuous agent succeeds primarily because of her own practical wisdom-something that is not a matter of luck or good fortune. He puts the point best in the $E E:^{34}$

[5] We can see that some people are fortunate. For those who lack practical wisdom succeed in many things where luck rules; and also in areas where there is a craft, but where there is also scope for luck, for instance in the case of generalship and navigation. [...] That they do not succeed by practical wisdom is evident. For practical wisdom is not without an account-it can account for why it is acting in this or that way-but the fortunate would not be able to say why they succeed (for that would be a craft). That they succeed is obvious, though they are lacking in wisdom in the very things in which they are fortunate, and not just in other matters. [...] For in navigation it is not the most clever who are fortunate, but it is as in dice where one man throws a blank and another throws a six in accordance with his natural good fortune, or through being favored, as they say, by a god, so that success is the result of something external. (VIII.2 1247a3-24)

Aristotle characterizes the fortunate here as those who succeed without the sort of wisdom relevant to their activity. In some cases, this is because there is simply

\footnotetext{
${ }^{34}$ Here I adapt Kenny's translation (following with him Jackson's addition of $\epsilon^{\prime} \xi$ at 1247a23). There are many questions about this passage that I will not touch upon here-for instance, whether it is meant to be consistent with Aristotle's treatment of luck in the Physics (on which see for instance Johnson (1997), Johnson (2015), or Woods (1982: 167)), and whether it is meant to suggest that good fortune could yield endaimonia, or, less strongly, a kind of "doing well” ( $\epsilon \dot{v} \pi \rho \alpha \gamma i \alpha)$ that amounts to something less than this (see Johnson (2015) for the former view, and Kenny (1992: 57) or Ponesse (2012: 321-22) for the latter-and also Buddensiek (2012: 177-82) on the broader relevance of good fortune to our happiness). For my purposes what matters is the contrast drawn in this passage between good fortune and practical wisdom as distinct sources of success. The contrast can be understood without taking a stance on these broader interpretive disputes. (I do disagree with Cooper (1985: 193-95), whose reading downplays the impact the success of the virtuous would have on their happiness, except as a precondition for further virtuous activity.)
} 
no wisdom to be found: nobody is clever at dice, and if they throw sixes their entire life that can only be the result of their enduring good fortune (either their natural good fortune or else the fortune they receive as a favor from a god). In other cases, though there is room for wisdom, the activity leaves a lot to chance. Navigation is indeed a craft (cf. EN 1112b5), but even a skilled navigator doesn't always succeed at reaching their destination. For success at navigation is especially prone to disruption by external forces: inclement weather might sink the saltiest captain, while a complete novice might yet reach their port on a sunny day. To succeed at navigation requires some knowledge and deliberative skill, but also, invariably, some amount of luck-even once all the prerequisites for navigating are in place. ${ }^{35}$

To the extent that success at navigation depends on luck, it does not depend on the navigator's wisdom. For to get lucky, Aristotle tells us here, is to succeed without knowing the reason for one's success, and the practically wise know why they succeed. Indeed, this is one of the key ways in which Aristotle takes the sort of practical wisdom distinctive of the virtuous to be similar to the knowledge of a craftsman: practical wisdom and craft are both states "with reason" ( $\mu \epsilon \tau \grave{\alpha}$ $\lambda o ́$ ov), the former concerning how we should act, the latter how to produce things (EN VI.4 1040a3-5). ${ }^{36}$ So the success virtuous agents find in achieving their ends, when they succeed, should not be ascribed to some external good fortune. For the virtuous succeed thanks to their practical wisdom, and success that results from practical wisdom does not result from good fortune.

If this is right, we can see why Aristotle would think that cooperative externals could not be a decisive factor in determining our happiness. Recall that Aristotle thinks cooperative externals are goods controlled by luck-the sorts of goods that contribute to the successful performance of some activity in a way that goes beyond what we can achieve by our own devices, and in particular by means of our practical wisdom. To say that such goods determine our happiness would thus imply that luck determines our happiness. But as he tells us here, the success of the practically wise is due to their wisdom-and so not due to luck. And this is so even when these cooperative externals do in fact contribute something to an activity's success: as Aristotle emphasizes at Pol 1332a25ff, the craft of the lyre player is the cause of her artful lyre playing, even though a good lyre might help her fully display her skill. In the same way, the practical wisdom of a happy person is the primary cause of her happiness, even though certain cooperative

\footnotetext{
${ }^{35}$ Given Aristotle's mention of Socrates at $1247 \mathrm{~b} 15$, this example is probably meant to remind us of the discussion of wisdom and good fortune at Euthydemus 278-282, and in particular of the case of navigation and perilous seas mentioned at $279 \mathrm{e} 4-6$. On the respective roles of wisdom and good fortune in this passage, see Jones (2013: 6-8).

${ }^{36}$ See also EN VI.5 1140b20ff and VI.13 1144b16ff.
} 
externals might help her virtuous activity unfold in the best possible way.

What exactly distinguishes the contribution made by cooperative externals from the contribution made by an agent's wisdom? Aristotle never says. ${ }^{37}$ But a plausible suggestion, given his descriptions of craft-knowledge and states "with reason," is that the practically wise are capable of bringing about both some result and its opposite: the lyre player can play the right notes but also the wrong ones, the practically wise engage in virtuous but also vicious activity. ${ }^{38}$ Cooperative externals "controlled by luck," by contrast, only contribute to some determinate end to which they are naturally suited-as Aristotle sometimes puts the point, they act "like fire burns... by some natural tendency" (Met A1 981b3-4; cf. also $\Theta 2$ 1046b6). Thus good lyres might serve to improve our playing, but do not also potentially make it worse; and cooperative goods in general assist us only in bringing about some specific end we've already set ourselves, and which we could bring about (perhaps less well) in their absence. ${ }^{39}$

Implicit in Aristotle's treatment of external goods, then, lies the thought that these goods play a secondary role in the case of virtuous activity: our happiness is largely in our own hands because our practical wisdom is the primary cause of the successful achievement of our human function. Our wisdom is the primary cause of this achievement because it affords us a form of rational control in our activities: the wise are those who can generally bring about some result or its opposite by deliberate choice, independent of the contribution of some cooperative external-even where that contribution does align with their ends, and improve their activity. Thus while a shoemaker might make better shoes with better hides at his disposal, his craft lies in the fact that he "makes the best shoes out of the hides that are given him" (EN I.10 1101a4-5). So too, the virtuous do better with cooperative externals, but do not depend on them to succeed in their

\footnotetext{
${ }^{37}$ Nor does Aristotle specify how much could be left to chance before an activity is no longer said to "primarily" depend on the wisdom of its agent. Presumably there is a continuum: rolling dice doesn't depend on the agent's wisdom at all, navigation depends on it more, lyre-playing more still-and, as I'll be arguing, contemplation most of all. Navigation must reflect a navigator's skill enough to qualify as a craft, even if, among crafts, it leaves more to chance than others-on which point see fn.40 below.

${ }^{38}$ On this feature of craft-knowledge, see Met $\Theta 2$ 1046b5-25 and EN VI.5 1140b20-24. Of course the practically wise will never exercise their capacity for vicious activity, given their morally virtuous character. So while they could direct their wisdom towards vicious ends, as a matter of fact they will never be moved to do so. I am thankful to an anonymous reviewer for raising this point.

${ }^{39}$ One potential challenge here is that fellow soldiers are not the sorts of "lifeless things" (ă $\left.\psi v \chi \chi \alpha\right)$ Aristotle often uses in these examples, even though they can serve as cooperative goods. But Aristotle's thought may be that qua cooperators in our activity, these fellow soldiers do indeed serve only to assist us in some end we've set ourselves, just as any lifeless tool would. It remains true that qua deliberators they could, in their own actions, display the sort of rational control distinctive of the practically wise.
} 
virtuous activity.

And this, I think, is precisely the form of independence Aristotle associates with self-sufficiency in the Politics, when considering the resources necessary for an ideal, self-sufficient state. ${ }^{40} \mathrm{He}$ begins by noting that a state, like an individual human being, has a function to perform, and that the best state is the one best able to achieve this function (1326a13). A certain number of people will be necessary to do so-not too few, but not too many, either:

[6] A [state] that consists of too few people is not self-sufficient (and a state is self-sufficient), but one that consists of too many, while it is self-sufficient in the necessities, the way a group of people is, is still no state, since it is not easy for it to have a constitution. For who will be the general of its excessively large multitude, and who, unless he has the voice of Stentor, will serve as its herald?

Hence the first state to arise is the one composed of the first multitude large enough to be self-sufficient with regard to living the good life as a political community. It is also possible for a state that exceeds this one in number to be a greater state, but, as we said, this is not possible indefinitely. The limit to its expansion can easily be seen from the facts. For a state's actions are either those of the rulers or those of the ruled. And a ruler's task is to issue orders and decide. But in order to decide lawsuits and distribute offices on the basis of merit, each citizen must know what sorts of people the other citizens are [something excessive population makes impossible]. [...] It is clear, then, that the best limit for a state is this: it is the greatest size of multitude that promotes self-sufficiency in living and that can be easily surveyed as a whole. The size of the state, then, should be determined in this way. (1326b2-25)

So it does matter to the self-sufficiency of the state that it have enough people to be self-sustaining. But this only makes it self-sufficient as any group of people might be, that is, capable of providing the basic necessities for its citizens ( $а \dot{\tau} \tau \alpha \dot{\rho} \kappa \eta s$ $\omega \sigma \sigma \pi \rho \stackrel{\epsilon}{\epsilon} \theta \nu o s, 1326 \mathrm{~b} 4)$. The self-sufficiency of the state qua state is achieved when it has the power to successfully actualize its distinctive function through

\footnotetext{
${ }^{40}$ There is also, I think, an analogous technical use of "self-sufficient" at EN III.3 1112a34-

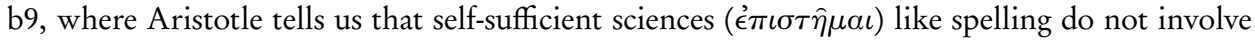
deliberation, whereas crafts like medicine, wealth acquisition, or navigation do. As Aristotle explains, such crafts are not as precisely worked out, and are concerned with things in which the outcome is obscure or indeterminate, while in matters of spelling there is no room for deliberation. Here the self-sufficient sciences are identified as those whose results are fully determined by the science itself and always brought about in the same manner, just as self-sufficient activities, on the view I've been defending, are activities whose unfolding is determined by their agent, and which do not depend on luck or good fortune. It's significant, in light of passage [5], that navigation is singled out in this context as being less worked out than a craft like gymnastics (1112b5-6).
} 
constitutional government-and this is impossible if the city is too large to be managed as a whole.

There is a clear parallel between Aristotle's remarks here and his insistence, in [3], that the self-sufficiency of contemplation "does not depend on excess" (1179a3). In both cases, there is a moderate need for external goods that serve as preconditions for achieving a function (some quantity of people in the case of a state, food and drink in the case of human beings). But in both cases, the degree of self-sufficiency of the person or state does not increase with the number of available goods. A state only truly counts as self-sufficient when it is successfully fulfilling its function as an entity unified by constitutional rule. So too, human beings only truly count as self-sufficient when they are the ones fulfilling their function, that is, when they rely least in their activity on the assistance of cooperative external goods. Self-sufficiency, then, is a form of independence: we need certain goods to act at all, but once these goods are in place we act self-sufficiently to the extent that we can achieve without external assistance what we set out to do. ${ }^{41}$

\section{Independence and Criterial Self-Sufficiency}

I've argued so far that self-sufficiency is a form of independence from external goods. Such an interpretation meets the two constraints outlined above. For the self-sufficiency of some activity is indeed diminished by our need for even the most basic goods: we depend on these goods as preconditions for the activity in question. But an activity's self-sufficiency is not increased merely by our acquiring the resources necessary to perform it: we might have all the resources we need but still depend, when performing the activity in question, on the assistance of cooperative externals. An activity will be more self-sufficient the less it depends on external goods for its successful performance-whether it depends on them as preconditions or as cooperative goods. Hence even once preconditions are accounted for, activities might exhibit varying degrees of self-sufficiency.

This helps us see, in particular, why virtuous activity exhibits a high degree of self-sufficiency. Virtuous activity does have some prerequisites-sometimes many prerequisites. But so do all activities. And once these are in place the success of virtuous activity, on Aristotle's view, depends primarily on our practical wisdom, rather than our good fortune or the assistance of cooperative goods. In this respect virtuous activity is more self-sufficient than an activity like throwing dice, say, even once we set aside the resources necessary for each activity (cf. [5]).

\footnotetext{
${ }^{41}$ I am thus in agreement with Gauthier and Jolif (1970: 52): "Être «auto-suffisant», c'est sans doute être comblé, mais c'est aussi et surtout être indépendant et c'est à cette indépendance qu'avant tout le Grec aspire."
} 
For achieving our human function, as Aristotle often insists, is largely up to us. Rolling sixes is not.

It also helps us see why contemplation would be the most self-sufficient form of virtuous activity, as Aristotle tells us in [1]. This is so not only because contemplation has relatively few prerequisites. That would be a rather weak point, since presumably many external goods are needed for contemplation to be possible-a society that allows for philosophy, an education that engages our rational capacities, and so on-and in any case Aristotle grants, in [1], that contemplation requires "the necessities of life" like any other activity. What's more significant is that, once these prerequisites are in place, contemplation depends least on the assistance of cooperative goods: the successful performance of our contemplative activity depends more on ourselves (and less on fortuitous external circumstances) than the successful performance of morally virtuous activity. For as Aristotle tells us, the most purely noetic activities rely least on luck ("there is most intellect (vovs) and reason where there is least luck, and most luck where there is least intellect," $M M$ 1207a4-6). Contemplation aims at no end besides itself (X.7 1177b2-3, 1177b20), and does not seek to realize any outcome that might be impeded by misfortune or a lack of tools. Friends might yet improve our contemplative activity by collaborating with us, but less so than they do in cases of moral virtue-being alone is a severe impediment on courageous (or generous, or just) activity, but only a minor impediment on our contemplation. For all these reasons contemplation is as independent as any human activity could be.

You might still wonder, however, whether this sort of reading is really compatible with the criterial use of self-sufficiency in I.7. For it's not immediately clear why this form of independence would be a feature of something that "on its own" makes our lives "choiceworthy and lacking in nothing," or how this criterion is meant to follow from self-sufficiency of the sort I've been describing. To address this point it will be helpful to consider some cases of things that fail to meet the I.7 criterion. For instance pleasure, or honor, or some combination of these, would have commonly been thought to make for a happy life, and thus taken to be the sorts of goods the pursuit of which makes our lives "lacking in nothing." ${ }^{42}$ But in fact, as Aristotle argues, the pursuit of honor would not on its own make our lives lacking in nothing. For honor depends on those who bestow it more than it does on those who receive it (I.5 1095b24-25). So we would have to add (at a minimum) that the pursuit of honor and its recognition by others,

\footnotetext{
${ }^{42}$ Lives characterized by the pursuit of honor or pleasure are just the traditional candidates for happiness, as Aristotle presents them in EN I.5 (setting aside the life of contemplation-the alternative Aristotle arguably ends up endorsing).
} 
taken together, make our life lacking in nothing. ${ }^{43}$ Thus honor itself cannot be eudaimonia. For endaimonia, as Aristotle emphasizes, is "our own, and hard to take away," while honor inevitably depends on others, and is thus never really up to us, and thus such that its pursuit could not by itself make for a happy life (I.5 1095b26).

A life of honor is lacking, then, precisely because the pursuit of honor is an activity that inherently depends on externals for its success. And it's in this sense, as I understand Aristotle, that it does not on its own make any life "lacking in nothing." We would always have to specify some external circumstances that do not reflect any achievement on our part, and that go beyond our own pursuit of honor, in order to make it count as a worthwhile pursuit. Virtuous activity, by contrast, does not depend on externals in this way: we do not need something else besides our own virtuous activity for our virtuous activity to go well (or at least, we do not need much else-the virtuous still need certain resources, and are certainly not completely immune to misfortune). This is akin, in language and in content, to the conclusion drawn about wisdom in the Eutbydemus: once someone

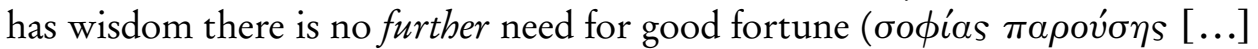

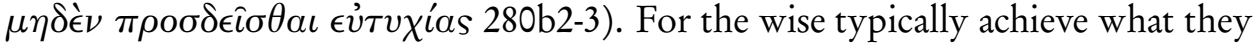
set out to do, and do so primarily thanks to their own practical wisdom.

As I understand Aristotle, then, to say that endaimonia makes a life "lacking in nothing" is not to say that there is nothing at all a happy person could reasonably wish for. Even a happy person could wish for further goods-avoiding certain minor misfortunes, being bestowed greater, well-deserved honors, enjoying more simple pleasures, and so on. A happy life can surely be made better or worse in various ways. ${ }^{44}$ The thought is only that once we are happy we do not need to specify some further goods, besides our own eudaimonia, on which our happiness would depend-in the way a life spent pursuing honors would always depend for its value on the recognition of others. Of course this remains an ideal we human creatures cannot fully realize: some externals are always needed for our human activities to succeed. ${ }^{45}$ But virtuous activity's high degree of independence from externals makes it a good candidate in this regard, and contemplation's even

\footnotetext{
${ }^{43}$ And further, we would have to specify that the honor be recognized by the wise. And since the wise honor virtue, Aristotle goes on to argue, this would just amount to saying that virtue makes life lacking in nothing-though he thinks we would still have to specify that virtuous activity is required, not just a virtuous character. There are thus many reasons why honor is not endaimonia. But one important one is that it always depends on externals, and so does not on its own make our lives lacking in nothing.

${ }^{44}$ As is convincingly argued in Cooper (2003: 288) and Lear (2004: 60-62). See also Heinaman (1988: 42) and Lear (2004: 65) on Aristotle's subsequent claim that happiness is the most choiceworthy good "not being counted together" with these goods (1097b16-20).

${ }^{45}$ Aristotle's god, as pure activity, would presumably be ideally self-sufficient.
} 
higher degree of independence from externals makes it an even better one.

It is less clear, I concede, why this sort of independence would itself make our lives choiceworthy ones. After all, a solitary life led in pursuit of simple pleasures might not depend on any great quantity of external goods, in either of the roles I've described, but it wouldn't thereby be a life worth choosing. ${ }^{46}$ I think there are two possible answers here. One would be to say that Aristotle's criterion in I.7 is slightly more restrictive than his core notion of self-sufficiency-in that it rules out activities that exhibit a high degree of independence from externals but do not make our lives ones worth choosing. This would not affect Aristotle's substantive conception of happiness: a life of simple pleasures would in any case be ruled out by his function argument. Indeed, it's probably something anyone committed to a univocal interpretation of self-sufficiency would have to grant, given that Aristotle does sometime speak of the self-sufficiency of beasts (Pol 1253a29), presumably without thinking beasts have lives worth choosing. Another possible answer would be that Aristotle simply values independent achievements, and that in the specific case of achieving our buman function, he takes the sort of independence I've been describing to contribute to the choiceworthiness of our lives. This is not something Aristotle says directly, but he plainly takes the fact that we achieve happiness by our own means to be one of the features that make it a noble, praiseworthy thing (cf. 1098b30ff). If this is right not all independent activities are choiceworthy, but achieving our human function is, and part of what makes this particular achievement choiceworthy is that we are the ones responsible for it.

One last consideration in support of this interpretation. Commentators have rightly noted that Aristotle takes the self-sufficiency of some good to serve as a mark of its finality-a point which draws on Plato's discussion of these notions in the Philebus. ${ }^{47}$ That may seem hard to square with what I've said so far. For it may seem that a good could depend on externals yet still exhibit a high degree of finality-that is, still be a good whose value does not stem from some product or outcome beyond itself. ${ }^{48}$ If that's right, a good could fail to be self-sufficient and nonetheless be final, and so self-sufficiency would be rather poor evidence for finality. But at least as far as activities are concerned, I think we can make

\footnotetext{
${ }^{46}$ In the Philebus passage that influenced Aristotle's treatment of happiness, Socrates presents three criteria for the good: sufficiency, finality, and choiceworthiness. As Cooper has argued, Aristotle's self-sufficiency can be seen (roughly) as a combination of Socrates' sufficiency and choiceworthiness criteria (2003: 283). Perhaps one lesson here is that this combination comes at a cost.

${ }^{47}$ On the connection between these two criteria, see e.g. Cooper (2003), Heinaman (1988: 45), and Lear (2004: 51-53). Aristotle makes the point most clearly at 1097b5-8 and 1176b1-7.

${ }^{48} \mathrm{~A}$ good party, for instance, might be thought to require a lot, but still not depend for its value on some further end beyond itself. Thanks to an anonymous reviewer for this example and for pressing this point.
} 
sense of Aristotle's suggestion here. ${ }^{49}$ For it's reasonable to think that activities that are final are also self-sufficient: a final activity is not performed for the sake of something else, and so it's no surprise that our performing it successfully would not depend on something external to the activity itself, like the assistance of some cooperative good. The thought here is simply that activities which depend on externals for their successful performance are unlikely to be final activities, because the dependence at play often stems from our attempting, when performing the activity, to bring about some effect or product beyond the activity itself, for the sake of which the activity is performed. Thus activities that fail to be self-sufficient, at least in many typical cases, will also fail to be final.

If this is right, final activities are indeed self-sufficient, and moreover selfsufficient to the extent that they are final. Contemplation, in particular, is more final, and thus less dependent on outcomes than other forms of virtuous activityand more self-sufficient as a consequence. For, in Aristotle's words, "nothing arises from it apart from the contemplating, whereas from practical activities we gain more or less apart from the action" (1177b2-4).

\section{Conclusion}

I've argued in this paper that the notion of self-sufficiency Aristotle invokes in his ethical works is best understood as a form of independence, in our activities, from external goods. We depend on some of these goods as preconditions for our happiness: though they do not make us happy on their own, we need them to act virtuously and avoid an outright miserable fate. We depend on others as goods that cooperate with us in our activity: they play a role analogous to that of a craftsman's tools, assisting us in our virtuous endeavors and ensuring they succeed unimpeded, and contribute to our happiness as much as they might.

Virtuous activities often have many preconditions, and our need for these preconditions does set a limit on our self-sufficiency. But any human activity will depend on preconditions of some sort. What's distinctive about virtuous activity is that, once the preconditions are in place, its successful unfolding depends on us more than fortuitous circumstances or further cooperative goods. We need material goods for dice-throwing, just as we do for virtuous activity, but success at dice does not depend on the dice thrower in the way successful virtuous activity depends on the virtuous individual. For the morally virtuous individual will know how to act in a variety of circumstances, and how to reliably achieve her ends-something she does better unimpeded, and with the right tools, but which

\footnotetext{
${ }^{49}$ This is therefore one place where it seems to me important to think of eudaimonia as an activity rather than some collection of goods.
} 
ultimately depends on her practical wisdom rather than these tools or her general good fortune.

The philosopher exhibits this independence most of all: contemplation has few prerequisites, and, as a purely noetic exercise which does not seek to bring about some outcome distinct from itself, depends least on good fortune or the assistance of external cooperative goods. Thus contemplation "on its own," unassisted and with minimal reliance on externals, makes our life "lacking in nothing," that is, lacking in no further good, independent of our contemplative activity itself, that would be needed to make our life count as a flourishing human life. It's in this sense, I suggest, that we should understand Aristotle's claim that eudaimonia is self-sufficient, and contemplation most self-sufficient form of virtuous activity. ${ }^{50}$

\footnotetext{
${ }^{50}$ An early version of this paper was presented at UT Austin for the 35th Annual Ancient Philosophy Workshop. I am grateful to its members, and David J. Riesbeck in particular, for their helpful questions and comments. Thanks also to Rusty Jones and Gisela Striker for their guidance and encouragement, and to two anonymous reviewers, whose detailed feedback led to a number of significant improvements.
} 


\section{References}

Ackrill, J. L. (1974). "Aristotle on Eudaimonia." Proceedings of the British Academy, 60, 339-359.

Broadie, Sarah (1991). Ethics With Aristotle. Oxford University Press.

Broadie, Sarah and Christopher Rowe (2002). Aristotle: Nicomachean Ethics. Oxford University Press.

Brown, Eric (forthcoming). "Aristotle on the Choice of Lives: Two Concepts of Self-Sufficiency." In Quel choix de vie? Études sur les rapports entre theôria et praxis chez Aristote (Pierre Destrée, ed.), Peeters.

Buddensiek, Friedemann (2012). "Does Good Fortune Matter? Eudemian Ethics VIII.2 on Eutuchia." In The Eudemian Ethics on the Voluntary, Friendship, and Luck (Fiona Leigh, ed.), 155-184, Brill.

Cooper, John (1975). Reason and the Human Good. Hackett.

Cooper, John (1985). “Aristotle on the Goods of Fortune.” The Philosophical Review, 94, 173-196.

Cooper, John (2003). "Plato and Aristotle on 'Finality' and '(Self-)Sufficiency'." In Plato and Aristotle's Ethics (Robert Heinaman, ed.), 117-147, Ashgate.

Curzer, Howard J. (1990). "Criteria for Happiness in Nicomachean Ethics I 7 and X 6-8.” The Classical Quarterly, 40, 412-432.

Devereux, Daniel (1981). "Aristotle on the Essence of Happiness." In Studies in Aristotle (D. O’Meara, ed.), 247-260, Catholic University of America Press.

Gauthier, R. A. and J.-Y. Jolif (1970). L'Éthique à Nicomaque. Publications universitaires de Louvain.

Heinaman, Robert (1988). "Eudaimonia and Self-sufficiency in the Nicomachean Ethics.” Phronesis, 33, 31-53.

Hitz, Zena (2011). “Aristotle on Self-Knowledge and Friendship.” Philosophers' Imprint, 11, 1-28.

Irwin, Terence (1999). Nicomachean Ethics, second edition. Hackett.

Johnson, Kent (1997). "Luck and Good Fortune in the Eudemian Ethics." Ancient Philosophy, 17, 85-102. 
Johnson, Monte Ransome (2015). "Luck in Aristotle's Physics and Ethics." In Bridging the Gap between Aristotle's Science and Ethics (Devin Henry and Karen Margret Nielsen, eds.), 232-253, Cambridge University Press.

Jones, Russell E. (2013). "Wisdom and Happiness in Euthydemus 278-282." Philosophers' Imprint, 13, 1-21.

Kenny, Anthony (1992). Aristotle on the Perfect Life. Oxford University Press.

Keyt, David (1978). "Intellectualism in Aristotle.” Paideia, special issue 2, 138157.

Kraut, Richard (1989). Aristotle on the Human Good. Princeton University Press.

Labarrière, Jean-Louis (2003). "Comment vivre la vie de l'esprit ou être le plus soi-même." In Aristote: bonheur et vertus (Pierre Destrée, ed.), 79-106, Presses Universitaires de France.

Lear, Gabriel Richardson (2004). Happy Lives and the Highest Good. Princeton University Press.

Nussbaum, Martha C. (2001). The Fragility of Goodness: Luck and Ethics in Greek Tragedy and Philosophy, revised edition. Cambridge University Press.

Ponesse, Julie E. (2012). “'E $\nu \theta o v \sigma \iota \alpha \sigma \mu$ ós and Moral Monsters in Eudemian Ethics VIII.2." Journal of the History of Philosophy, 50, 315-337.

Reeve, C.D.C. (1992). Practices of Reason: Aristotle's Nicomachean Ethics. Oxford University Press.

Ross, William D. (2009). Aristotle: The Nicomachean Ethics. Oxford University Press. Revised with notes by Lesley Brown.

White, Stephen A. (1990). "Is Aristotelian Happiness a Good Life or the Best Life?” Oxford Studies in Ancient Philosophy, 8, 103-144.

Whiting, Jennifer E. (1986). "Human Nature and Intellectualism in Aristotle." Archiv für Geschichte der Philosophie, 68, 70-95.

Woods, Michael (1982). Aristotle: Eudemian Ethics Books I, II, and VIII, second edition. Oxford University Press. 